\title{
Black, Young \& Conduct Disordered: Extrapolating Scott Henggeler's Multisystemic Psychotherapy Paradigm for the Attenuation of At-Risk Behaviors of Black Youth in North America
}

\author{
Buster C. Ogbuagu, PhD \\ Chair \& Associate Professor, College of Arts \& Sciences, \\ Department of Social Work, University of St Francis, Joliet, Illinois, USA
}

Doi:10.19044/esj.2018.v14n20p89 URL:http://dx.doi.org/10.19044/esj.2018.v14n20p89

\begin{abstract}
Problem Statement: More than any other racial category, Black Youths have experienced severe racial disparities in contravention, trial and incarceration rates, the moment they come in contact with law enforcement agencies. There is a growing amount of literature suggesting that implicit racial biases do indeed exist in those who enforce the law, especially when such enforcers have limited time or and lacked cultural competencies to process their actions. These disparities are troubling, especially on account of the fact that although Black Youth comprise 16 percent of all children in America, yet they account for 28 percent of all juvenile arrests (National Council on Crime \& Delinquency, 2007). It is not to imply that Black youths do not commit crimes. They do, just like all other ethnically diverse populations. However, there are research findings that Black youth pay a rather heavy premium for engaging in criminal or anti-social behaviors, mostly on account of their race, socioeconomic backgrounds, which are saturated by the stereotypical absence of a father or father figure, matriarchies, poverty and being mired in poor neighborhoods on one hand and on the other, a criminal justice system that disproportionately targets them. Approach: The paper applied an extrapolation of Scott Henggeler's Multisystemic Psychotherapy paradigm to evaluate how its application can assist in stemming Black Youth lemming-like rush into the juvenile and criminal justice systems. It utilized secondary data analysis and literature on Black youth, juvenile, criminal justice and conduct disorders to evaluate this therapeutic approach in a Large Group Intervention-LGI setting. Result: Research indicate that the Multisystemic Therapy approach had previoulsy been applied at a micro level with satisfactory outcomes. In this case, I propose a treatment paradigm intended to be extrapolated [from Henggeler's approach] to a Large Group Intervention-LGI and community setting, using all the
\end{abstract}


parameters as Henggeler and team enunciated, but with slight adjustment and modifications to fit a Large Group Intervention target audience. Conclusion: The successful application of Hengeler's Therapeutic Model within a Large Group Intervention setting significantly attenuated negative Black Youth interaction within the criminal justice systems in the USA, Canada and elsewhere. Additionally, successful application of this paradigm enhanced Black Youth pro-social skills for the development of the self, community and the nation states where Black Youths call home.

Keywords: Black Youth, Conduct Disorder, Criminal Justice System, Sentencing Disparities, Large Group Intervention, Psychotherapy, Multisystemic Therapy-MST.

\section{Introduction \& contextualization:}

Conduct disordered and anti-social behaviors in children and adolescents have been in existence since primordial times (Weijas, 2004). In this respect (Burkhead, 2001), it has shared the same continuum as prosocial or "normal" behaviors to the extent to which both socially constructed categories have similar patterns of development, persistence and paths of change. Contingently, conduct disorder can be surmised to be the consequence of failure to internalize socially accepted and normative modes of negotiating the environment. A corollary to this is that according to Herbert (1987), conduct disorder assumes the acquisition and or internalization of deviant, socially sanctioned strategies for life and event negotiations.

Understanding conduct disorders among children and adolescents will have to take into consideration an assumption that it is universal and crosscultural. Its implications, based on several epidemiological data, is that management of its consequences are capital intensive. However, and as argued by Barn (1993), in as much as conduct disorders among children and adolescents is universal, its commission has presented as having more profound implications and ramifications for cultural minorities, mainly Blacks, in Britain, Canada and the United States. In the context of the American and Canadian mosaic, the implications for conduct disorder among Black Youth has tended to highlight the Black population in pathological terms. This is especially so in major cities of the American continent, having a large Black population, as well as a large number of children (Torczyner, 1997). How so? This is due to the fact that an observed overrepresentation of Black youths in the Juvenile and criminal Justice Systems in these countries is attributable to conduct disorder or the assumption thereof (Hutchinson, Nichols, Pare, \& Pepin, 1992).

This paper attempts to articulate conduct disorders, the outcome of these delinquent behaviors among Black Youths in North America precisely 
and how they conflict with the juvenile and criminal justice systems. It also explores, as an extrapolation, approaches to addressing conduct disorders among Black youth in the United States, a country that routinely subjects its delinquent youth to the punitive sanctions designed for adults. The paper also examines some efficacious treatment approaches, both in Canada and the United States to address or attenuate these conflicts with the systems. The paper has been delineated into seven parts, which concentration was not so much on the existence or prevalence among Black youths of this pathology, as it dwelt on efficacious approaches to prevent or ameliorate conduct disorders among this population. It is also aimed, and I propose especially exploring Large Group Intervention-LGI therapeutic treatment modality, which extrapolates from the "Henggelerian" Therapy paradigm to stem the mass incarceration of Blacks [Youth] in Canada and especially the United States (National Council on Crime and Delinquency, 2007).

In the first part, I examined Black Youth conduct disorders in terms of their externalizing manifestations, due to their frequent arraignment before the Juvenile Offenders and Criminal Justice Systems. This section also examined the epidemiological data, buttressing the burden of suffering on Black youth in both the United States and Canada. The second segment defined the developmental stages in the developmental pathway, which in this case were of children between the ages of 12-18 years. The third and most relevant aspect of this paper was my attempt to develop an intervention model to address Black youth conduct disorders in a bid to stem the tide of juvenile and adult adjudications. Here, I utilized the Large Group Intervention model as Henggeler's hybridized Multisystemic, multicomponents, and targeted approach to chip away at conduct and antisocial disorders, I subsequently arrived at the development of pro-social skills paradigms for diversion from the criminal justice systems in Canada and the USA. The Multisystemic Therapy paradigm is a derivative or assemblage of the Strategic Family Therapy, Salvador Minuchin's Structural Family Therapy (Vostanis, 2017) and Cognitive Behavioral Theraphy. I also attempted to streamline and justify other components of this approach in the fourth segment of the paper, such as location and group-focused setting.

The intervention modality located in the third part is the fulcrum of this paper, which hinged on the fourth and fifth segments of this research. Whereas the fourth component examined location and a Large Group[focused] Intervention-LGI, the fifth section reviewed some of the existing literature, aimed to underscore their relevance and efficacy in relation to the approaches submitted. The sixth section of the paper evaluated the suggested procedure for the purposes of measurement, sustainability and best practice. The last section in this exercise articulated some of the implications for practice, policy and future research of the Multisystemic Intervention Therapy 
approach, as well as the possibility of stimulating discussions on other preventive approaches for conduct disorder among Black youths and other juvenile populations at risk.

\section{Review of literature}

According the 1991 Canadian Census figures, there are approximately 504,290 persons designated in the social category called Black (Torczyner, 1997). Statistics Canada (2006) updates that number to 783,795. Going by the 1991 figures, a large chunk or 61 percent reside in Ontario, while 25.2 percent live in Quebec. There is a staccato or negligible presence of Blacks in other provinces across the rest of Canada. In this vein, and still according to these figures, the Canadian Black community is considerably younger than the Canadian population as a whole, with approximately 3 out of 10 members of the Black communities being under the age of 14 (Torczyner, 1997). The implications of these findings include the fact that the visibility of Blacks in Canada and the United States of America is highlighted by the higher percentage of young persons who are more active, visible and will definitely come into contact and mostly in conflict with the juvenile and criminal justice systems in the aforementioned countries. Further to this and according to Torczyner (1997), is that there are 6 percent fewer adult Black men than women in Canada, with twice as many Black women in the Black communities (8.1 percent in the Black population; 3.6 percent in the total population) as in the total population being single in 1991 . The natural corollary is that young persons in Canada and the United States will be residing in poor, single, female headed households or matriarchies, which is a recipe for all sorts of internalizing but mostly externalizing conduct disorders by the youth. Succinctly put, being Black and young in the United States or Canada, poor [including poverty accumulation neighborhood domicile], in a gendered, single parent family, present rather significant risk factors (Hemovich \& Crano, 2009; Dwivedi, 1993).

Walker, Spohn and Delone (1996) have suggested that the disproportionate percentage of Black youths and families highlighted in arrests, trials and institutional custody has underpinnings, not necessarily related to legal justice, but more manifestly to race, family dynamics, class and socioeconomic dispositions. There is significant and compelling literature to suggest that juvenile justice disparities are attributable to implicit racial bias. This bias is consistent with the knee-jerk and unconscious associations, mostly stereotypes that humans, especially those in racial power positions, formulate about racialized groups. Generally deemed stereotypes, implicit bias forces [triggers or activates behaviors] those in power positions to make a hasty, but inappropriate decision, with minimal reflection because of "othering". For instance, whereas only 12 percent of the United States 
population is Black, yet Americans of African descent accounted for 30 percent of individuals arrested for property offense and 38 percent of individuals arrested for a violent offense (The Sentencing Project, 2013). Still in consonance with our study, The Sentencing Project further argues that whereas Black youths in America comprise only 16 percent of all American children, the same, constitute 28 percent of all juvenile arrests.

One may ask why there is a lop-sided representation of Black Youth in the criminal justice systems, even when their population size may suggests otherwise. The only plausible rationale for this disparity in arrest rates is the idea that racialized entities commit crimes at higher rates, specifically males. Black males are stereotypically believed to commit violent and property felonies at higher rates than other racial types (The Sentencing Project, 2013). Those who disagree, strongly suggest other reasons for the higher rates, including socioeconomic factors, rather than race. The Sentencing Project opines further, that those whose residence and world exist only in disadvantaged, disenfranchised and poverty accumulaton neighborhoods, would become highly susceptible to higher rates of crime, irrespective of their racial or ethnic make-up.

For Cole (2013), it is like a self-fulfilling prophesy that 1 in 3 Black men will expect to spend time in prison in the United States. Cole (in Sentencing Project, 2013), puts it more poignantly:

These double standards are not, of course, explicit; on the face of it, the criminal law is color-blind and class-blind. But in a sense, this only makes the problem worse. The rhetoric of the criminal justice system sends the message that our society carefully protects everyone's constitutional rights, but in practice the rules assure that law enforcement prerogatives will generally prevail over the rights of minorities and the poor. By affording criminal suspects substantial constitutional rights in theory, the Supreme Court validates the results of the criminal justice system as fair. That formal fairness obscures the systemic concerns that ought to be raised by the fact that the prison population is overwhelmingly poor and disproportionately black (Pp.1-2).

\section{Methodology}

\section{Target population: Black youth \& their families in North America}

The selection of Black youths and their families for the intervention being proposed in this paper is informed largely by relevant studies and findings that this population has preponderance or overrepresentation in the welfare, juvenile and criminal justice systems (Hutchinson et al. 1992). The issue of overrepresentation of youths and families of African descent within 
the Protective services, juvenile as well as criminal justice systems has been a recurring decimal in most studies, written work and researches throughout Britain and North America, especially the United States and Canada (Mosher, 1997; Hawkins, 1995). Whereas the United States has conducted more research and accompanying literature and other materials on this issue, due, largely to the substantial number of Blacks in that country, Canadian research attempts are growing, but still rudimentary for the mere fact of the limited population of Blacks, in juxtaposition with the dominant culture (Mosher, 1997; Schissel, 1990).

Drawing an analogy with Montréal, Hutchinson et al. (1992) cited the 1986 Canadian Census, which implied that Anglophone Blacks represented 5.8 percent the population of in this city. To this extent, the issue of overrepresentation of Blacks in care was formally raised by Black Human Service Workers in 1988, when it presented a brief to senior management of the former Ville Marie Social Service Center. This brief, which described perceived barriers to providing services in the Black community was flagged as a most urgent and troubling problem. Based on this, Hutchinson et al. (1992), attempted to assess the proportion of children in care that were from the Anglophone Black community.

In furtherance of this brief, a cross-sectional study design involving a one-day census was carried out in December 1993, with the social work personnel in Mount St. Patrick Youth Center, Ville Marie Social Services Center, Shawbridge (Prevost Campus) Youth Center and Youth Horizons. Sequel to this survey, social services workers from the centers in the research population were each requested to complete a questionnaire for each juvenile client receiving services and care from the network. The findings showed that of the three thousand, six hundred and seventy-four $(3,674)$ children receiving services, 23 percent was Black. The findings further showed that in the 1990s, Black children in Montréal were four times more likely to wind up in care than were White children (Hutchinson, et al., 1992). Hutchinson, et al. research found that there are four major risk factors strongly correlated with the need for care: family income level; mother's educational level not being above grade school; large family size of four or more siblings; and one parent, female-headed or matriarchal families. These four major risk factors are even more evidenced by the disproportionate number of Black families requiring social service intervention in Montréal (Hutchinson, et al., 1992).

\section{Study design}

This is an ethnographic, qualitative study and proposal, using secondary data for analysis and comprising the application of observation or and intuition. Harlos et al. (2003) argue for ethnographic research as providing platform for thoroughly examining processes, and defending that process and 
attendant outcomes. Here are the methodological details of the qualitative research, beginning with the participant pool.

Group Therapy participants: The LGI Therapy Group that I propose will initially comprise 250 randomized at-risk Black youths and their families. Of these, 150 will comprise youths who have been adjudicated under the Juvenile Justice system in the United States and Young Offenders Act in Canada, therefore at risk for recidivism. The other 50 (control group) will be made up of youths who have never experienced the juvenile justice system, but have been known to engage in some delinquent activities. The last 50 will serve as a no contact, no treatment control group for assessing the efficacy of this prevention experiment. Participants will be randomly screened and selected, based on a volunteer, as well as mandated list, derived from the YOA Alternative Measures Program and other related programs across the United States and Canada (McCord, 1992).

\section{Developmental stage of participants}

The developmental stages that will be selected here are high school or the adolescence age cohort, from 12 to 18 years. Piaget (1932) has described the developmental pathway of adolescents within this age category as mercurial, changing radically from a position where rules were absolute, unquestionable and sacred, to one that is manmade, non-absolute, questionable, secular, therefore negotiable. At this stage also, and according to Piaget, the adolescent is beginning to come into regular contact with other youths, who may not share their views on morality and may indeed corrupt them by differential association. This leads the youth not only to extricate their thought process from its roots of experience, but also become imbued with propositional thinking that allows them to hypothesize and make consequences-laden deductions.

For Herbert (1987), the developmental pathway here also suggests that adolescents in urban environment, due to rapid social change and ease of communication-smart phones and social media, tend to acquire a significant amount of their values from outside of the family through their peers. These peers increasingly and subsequently take the place of their parents in interpreting and enforcing the moral code. Sutherland, Cressey \& Luckenbill (1992), argue that in this equation, when a negative peer group takes over the functions of parents, there is a development in the youth of a pathological attachment. They opined that on the same continuum, the rationale for the choice of this age cohort is that they are visible, active, transitioning into adulthood, presenting with internalizing, but especially, externalizing behaviors at home, school and society, and most likely to come in conflict with the systems (Hemovich \&Crano, 2009). This age cohort is the type designated 
under the Young Offenders Act-Canada or the Juvenile Justice system in the United States.

\section{Multisystemic, multi-component \& targeted intervention}

As the title of this paper implies, Black youths are a rather visible social category (Torczyner, 1997). To this extent, the intervention as proposed will be targeted, but through a Large Group Intervention-LGI multisystemic and multicomponents approach. The reason is that there are several variables that promote the development into these externalizing behaviors. Such variables include: single parent status, female status; poverty; neighborhood (Hutchinson, et al., 1992), labeling; racism and the lack of diversity competency training on the part of the mostly White practitioners. The intervention will aim to address those variables that have the potentials for bringing Black youths and their families into conflict with the juvenile and criminal justice systems.

Although some particularly challenging youths and their families could benefit from Individualized Intervention Plan-IIP, the intervention site that we propose will be a Large Group Intervention-LGI medium, also known as community-based, group-focused, with a school component. The argument is that community activities cannot be distanced from school and educational activities. It is argued by Curtis, Ronan \& Borduin (2004); Henggeler, Schoenwald, Borduin, Rowland \& Cunningham (1998); Henggeler \& Bordiun (1990); Minuchin \& Shapiro (1983) that the school is a major social institution, having profound influence on child development. In this context, children, especially Black youths discover that some of their parents' and culturally permitted behaviors, like boys wearing bandanas or weaving their hair can be problematic, when applied to their teachers and school environment. I propose a Large Group Intervention, which in this case initially comprises 250 Black youth for a number of reasons, including the argument of a Collectivized Lived Experience-CLE [including subjective labeling] of Black youth in North America by the systems. This argument proposes a "whole systems" paradigm (Ray, 1995), contingent on findings by organizational scholars and practitioners, who speak to the focus on the whole systems ecology as the vehicle of change. The Large Group Intervention-LGI, using the whole systems ecology model, argues for the ethological analogy of organizations being akin to living systems. Thus, these living systems, in order to survive and be sustainable, must engage in symbiosis to adapt and survive an environment that is in a constant state of flux, including hostile and inimical to their survival intentions. Ray further argues that the ability of systems to adapt to a changing environment, determines whether they "live, grow healthy or die." This shared experience has potentials to engender consciousness of 
the whole. LGIs are predicated on the emergence of the following assumptions:

\section{Underlying ethos of Large Group Interventions}

Engenderment, promotion and sustenance of a sense of interdependence and interconnectedness with others, who have experienced the same phenomena

Promotion of processes that bring a systems perspective to the events purpose

Realization of discernible outcomes through highly participatory and synergistic paradigms

Promotion of a sense of appreciation and positive affect for self, others, and the whole

Shared learning experience that builds trust and community

Enhancement of esprit de corps [we consciousness that says "we are one and the same and have achieved this as a group].

Promotion of the ability to hope and nurture a more satisfying future

\section{Limitations of the proposed intervention}

Perhaps, the most obvious limitation of the proposed intervention is the large number -250-participants expected to be a part of a Large Group Intervention-LGI Model. The sheer size may generate an unwieldy environment for its animators and practitioners. There are at least four dynamics of intervening with large groups under the Large Group Interventions paradigm that Bunker \& Alban (1997) have identified. Since the scope of this proposition precludes an in-depth discussion and analysis of the drawbacks, I shall name and briefly describe them as [1]. The dilemma of voice-this speaks to how participants may feel that their voices are not heard due to the large number. This perception of voicelessness may force them to withdraw emotionally, but often also physically. [2]. The second issue is the dilemma of structure-which speaks to the amount of time and energy allocated to steadying jittered nerves and anxiety among participants. If the structure is overwhelming, or too lax, they will inevitably impact on participation and its outcomes. Recall that the Black youth population in this study got in trouble in the first instance for their apathy towards structured environments. [3]. There is the issue of egocentric dilemma, which participants may indulge themselves in as they see the world only through their own prisms. This failure to see others' views may result in poor or limited outcomes. [4]. The fourth, as described by Turquet (1975) as Affect Contagion is often a behavior that is common among groups. Those in a group "feel" each other out, because they are with them and inevitably may become receptive to their group members' behavior. If this behavior is a positive type, then it may serve the program 
intent well. However, if the behaviors and affects are the negative types, they may scupper the program.

\section{What are the definitions of youth-related anti-social behaviors?}

All youths engage in various forms of antisocial behavior along their developmental pathways (James, Blair, Leibenluft \& Pine, 2015). In most cases, these antisocial behaviors present as isolated, mild and fleeting. In a few others, these antisocial behaviors become repetitive, persistent and may burgeon into psychiatric designation of conduct disorder or oppositional defiant disorder as described by the American Psychiatric Association (2013) Diagnostic and Statistical Manual of Mental Disorders (DSM-5). To this extent the treatment regimen for the conduct disordered youths could and are often applied to juvenile offenders. Although I will not be going into the details of this definition due to the scope of this paper, suffice it to say that an antisocial behavior emerges as a conduct disorder when, according to Henggeler, Schoenwald, Borduin, Rowland \& Cunningham (1998), at least three of the listed antisocial behaviors occur within a twelve-month period. The list is endless, but some of them include starting fights, bullying, threatening peers, physical cruelty/aggression, using weapons, stealing, breaking and entering, and arson, vandalism, lying consistently, going AWOL and staying out until very late. A corollary to this is that this pattern of antisocial behavior presents with negative underpinnings for or impairment in the youth's social, academic or occupational functioning.

Black youths in North America, who have come under the Juvenile Justice dispensation, have been documented as presenting with some of the above-listed delinquent, conduct or antisocial behaviors (The Sentencing Project, 2013). Contingent on this assumption, the treatment model that will be adopted in this paper will follow the MST or Mutisystemic Treatment/Therapy approach as popularized by Henggeler et al. (1998) under their Nine Principles. The MST approach is pertinent to Black youths at risk and their families due, to a postulation by Russell (1998); Henggeler (1996); Joseph (1994); Li (1990) that serious antisocial behavior, including delinquency and crime are multidetermined by the reciprocity and apparent symbiosis between the individual youth and the important social systems with which youths come into contact, interact with and in conflict-family, peer, school and teachers, police and law-enforcement agents, neighborhood and community. In light of this, there is a note of caution here that although the MST approach as prescribed by Henggeler and his team is often Home-Based and Individualized, our intention is to adapt this approach instead to a Community-Based and Large Group Intervention Model among Black youths in North America and elsewhere. Paradoxically, MST was originally designed in the United States as a group therapy in a University setting (Medical 
University of South Carolina, n.d.), but was abandoned for the Home-Based and Individualized type due, to the high level of participant attrition. The following are the nine principles under which Henggeler's treatment paradigm operates and which we intend to adapt, with modifications that extrapolate to the proposed LGI paradigm.

Extrapolating the Clinical foundations of Henggeler's Mutisystemic Therapy (MST):

Nine Treatment Principles pertinent to Black Youths \& their Families within a Large Group Intervention setting:

Principle 1: To understand the fit between the identified problems and their broader systemic context.

Principle 2: $\quad$ Therapeutic contacts emphasize the positive and apply systemic strengths as vehicles for change.

Principle 3: Promote responsible behavior and decrease irresponsible behavior among the youths and their family members.

Principle 4: Present-focused and action oriented intervention, targeting specific and well defined problems

Principle5: $\quad$ Targeting sequences of behavior within and between multiple systems that maintain the identified problems

Principle 6: Developmentally relevant to the needs of the youth.

Principle 7: Require daily or weekly effort by family members.

Principle 8: Intervention effectiveness is continuously evaluated from multiple perspectives and assumption of accountability by providers to overcome successful outcome barriers.

Principle 9: To promote treatment generalization and long-term sustenance of therapeutic change through caregivers' empowerment to negotiate family members' needs with complex multiple systems.

The scope of this paper precludes an in-depth analysis of the nine principles. In this case, I have attempted to summarize and extrapolate each of these nine principles to a Large Group Intervention-LGI setting that I propose to address some of the antisocial behaviors among Black youths and their families, which often brings them at cross-purposes with the Juvenile and Criminal Justice Systems.

Principle 1: To understand the fit between the identified problems and their broader systemic context.

In the 1990s, had significant contact with Black communities and professional interventions as probation officer or Youth Delegate in the Bathshaw Youth \& Family Centers, Young Offenders services, with Black youth and their families in Montréal. My interventions were within the 
meaning of the Canada Youg Offenders Act. Here, I found that Black youths do not seem to think that they are fairly treated by the systems, including the school, community, and especially the law enforcement agencies (Hutchinson, et al., 1992). The group process will focus on how a lax parental supervision will lead to a Black youth breaking curfew, "hanging out" with aggressive and antisocial peers, and coming into contact with the police late at night. It will also address how the application of stereotypical, racist and pejorative language by teachers at school and the "trigger-happy" "Zero Tolerance" (American Psychological Association, 2008) system of expulsion from school [often targeted to Black Youth] will increase rebellion and oppositional behaviors by Black youths. These punitive measures lead the mostly, the emotionally fragile and risk types to either act out with dire consequences, or drop out of school. Worse still, they provide the seed money for the infamous School to Prison Pipeline phenomenon (Mallet, 2016). In this regard our treatment method implied multimethod, multirespondent approach. These approaches assess and highlight the strengths of each youth and family in the group process, in a bid to attenuate the negative precipitates of these variables.

\section{Principle 2: Therapeutic contacts emphasize the positive and apply systemic strengths as vehicles for change.}

Where the existence of multiproblem families-drugs and child maltreatment or abuse is not an issue with the families in this group process, I used strength based approaches that seek to engage Black families in treatment collaboration. Additional to this would be supportive therapeutic alliance that de-focuses on the youth's and family's deficits. It is already enough that Black youths and their parents face stereotypes and pathologizing in their everyday lives. Our aim will be to emphasize on strength-focused attitudes and interactions, to reduce negative affect. A reduction in negative affect proposes to enhance both the participants and staff morale that will establish the atmosphere for cooperation and mutual respect. Strength-focused attitudes and approaches will include avoiding pejorative and stereotypical language; applying the technique of reframing or joining; liberal use of positive reinforcement; incorporating and maintaining a problem-solving posture. For the Black youth and their families in Large Group Intervention MST, the appearance and provision of hope can mean the difference between change and a pathological quagmire. We intend to include linking families to community supports such as Instrumental, including financial; Emotionalempathy; Appraisal-affirmation or positive feedback, positive reinforcement, highlighting and praising what the youth and family are really good at; and Information-on resources. The scope of this discourse precludes in-depth analysis of these support paradigms. 
Principle 3: Promote responsible behavior and decrease irresponsible behavior among the youths and their family members.

Argue Hemovich \& Crano (2009), conduct disordered or antisocial behaviors almost always brings youths into conflict with the law. For Black youths, the probability is higher and outcome more profound (Sentencing Project, 2013), due to their distinctness from the dominant culture. This hybrid [LGI] MST appears to be significant in achieving prosocial outcomes to reduce antisocial behavior, arrests, out-of-home placements and improved family functioning. It is my summation that this preventive hybrid MST will appear to the youth, family members, school personnel, social workers, legislators and juvenile judges as less challenging/confrontational and costeffective. It is also achievable than the challenges of psychopathology, which "piggybacks" fixed, disease-like diagnostic labels of borderline personality disorder, conduct disorder, etc. (Henggeler et al., 1998).

Some of the suggested responsible behavior-producing interventions that could be applied to Black youths include:

* Assisting youths understand and make input on the rationale behind the rules of behavior

* Clearly defining consequences in advance to fit the nature of the behavior or transgression

* Applying social and overt reinforcers to promote responsible behaviors-e.g. praise

* Using aversive discipline to effect behavior modification-e.g. television, Internet, telephone

* "Making the time fit the crime." In this regard, some of the frustrations expressed by most of the Black families that I have intervened with, seems to be that the system always "throws the book" at them (Henning, 2013). At the Young Offenders justice system, I once intervened with a young, Black girl, which sole reason for being adjudicated was using a felt pen to scribble on the glass panels of a bus shelter on her way home from school. The negative and obviously racially motivated outcome of this adjudication would be that the child could come into contact with other hardened delinquent youths and peers, as well as recidivating. Henggeler \& Bordiun (1990) insist that peer group policies of schools and juvenile justice systems, which place troubled youths together in a classroom or treatment group, ostensibly to ameliorate or modify delinquent behavior, may indeed sometimes exacerbate the youth's difficulties (Sentencing Project, 2013; Hemovich \& Crano, 2009).

* Avoiding making punishment last so long that the youths perceive themselves as having little to lose by transgressing 


\section{Principle 4:Present-focused and action oriented intervention, targeting specific and well defined problems}

Presenting focused intervention will aim to change some of the current apparently dysfunctional family dynamics (Hemovich \& Crano, 2009), as a fulcrum for altering their future functioning, rather than dwell on the youth's and family's past. This aspect of MST suggests foregoing Freudian psychoanalysis and Bowenian family therapy (Brown. 2008; Miller, Anderson $\&$ Keala, 2004). Being action oriented means activating the family and its social environment to make rapid, multiple, positive, discernable and sustainable changes to long-standing pathologies (Bunker, 2005, 1992a). The limitations to these expectations will be discussed later in the paper.

Other aspects of the $4^{\text {th }}$ Principle according to Henggeler et al. (1998), include what is referred to as overarching and intermediate goals. In the overarching paradigm, Black youths and families are expected to identify a definite, expected outcome at the end of treatment. It could be that the Black youth, who dropped out early on, would now complete high school. Intermediate goals are those daily and on-going prerequisite activities that will assist in the accomplishment of the overarching goals. In the case of the Black students' school dropout, it may entail studying for exams, completing homework or requesting extra help with challenging subjects.

\section{Principle 5:Targeting sequences of behavior within and between multiple systems that maintain the identified problems}

A significant implication of MST and one that not only differentiates it from other treatment approaches, but also makes the hybridized LGI model relevant to Black youths at risk is the emphasis on interrelationships between systems that become hallmarks of identified problems (Schoenwald, Heiblum, Saldana \& Henggeler, 2015). In this vein, MST strives to empower Black parents to disengage their youths from antisocial or delinquent peers, while simultaneously filling the vacuum so created by encouraging their association with prosocial peers or groups.

The pertinence of this approach for Schoenwald, Heiblum, Saldana \& Henggeler is the eschewment of stereotypical assumptions common with other models. These flawed models perceive families with conduct disordered children to have a dysfunctional family dynamics, requiring parent training, communication training or problem-solving skills. In the case of MST, although its tenets for targeting desired familial interactions for change are individualized, what will be learned in the LGI therapy or process such as I am proposing can be tailored and adapted to meet the diversified needs of each of the families, participants and non-participants alike.

Candidly speaking, Black youth and their families in the United States and Canada are not monolithic structures, due to differences in geographical 
areas of origin, language, and experiences. Yet, they all face externally imposed social categories of nomenclarization in terms of color, race, discrimination, sometimes, harassment and social exclusion (Sentencing Project, 2013; Dwivedi, 1993). Peters and McMahon (1996) appear to be buttressing the $5^{\text {th }}$ Principle as postulated by Henggeler et al., (1998), by suggesting that individuals would "put their best foot forward" when they feel in control. This control that leads to some form of ownership of their lives, also engenders commitment.

In the case of single mothers of Black youths at risk, being in control is particularly important due, to the historical antecedents of slavery and racial discrimination. It is true that parents, especially Black single mothers cannot always change environmental factors. However, through a Large Grouporiented Intervention MST, they can learn and internalize how to alter perceptions that may strengthen or diminish beliefs in their parenting capabilities. To this extent, parental engagement in group processes within the Black community, under the LGI modified MST, will influence their ability judgment, increase their self-esteem and determine the extent of satisfaction with their accomplishment.

Some of the ways to increase parental self-efficacy and control, according to Peters and McMahon (1996) include:

1. Integrating self-management and self-control strategies into the intervention protocol

2. Assisting parents to negotiate and come to terms with the demanding nature of parenting, especially since Hemovich \& Crano (2009); Torczyner (1997) suggest that there are more Black, poor, single, female-headed house-holds, with young children and adolescents living in poverty accumulation neighborhood in North America than other continents. Added to this variable of single, Black, female parenthood are poverty, large number of children, lower social and economic mobility and racial discrimination on the part of law enforcement and social services agents.

3. Assist Black parents come to terms with their own imperfections, since there is neither an ideal parent out there, nor is there an absolute manual for parenting children (Vitaro, Brendgen \& Wanner, 2005). This will also assist Black parents de-internalize the ascribed stereotypical pathology of the Black family

4. Encourage acceptance, understanding and respect for their child's unique character and perspective

5. Anticipate, strategize a plan of action and problem-solve in advance to prevent an undesirable outcome

6. Model decision-making processes with respect to the child and family dynamics. 
Still on the $5^{\text {th }}$ principle, some identifiable problems with the Black youth, which will be highlighted in the group process, for the fact that they inevitably bring them into conflict with the law, are anger and aggression (Mouridsen, Rich, Isager \& Nedergaard, 2008). Sometimes, although the anger and aggression, when prejudicially triggered are justified, but the ways the youths react to this prejudice may be their undoing (Gardner, 1999). Due to the scope of this paper only the required steps for addressing anger and aggression with Black youths during the Large Group Intervention process are enunciated (Rose, 1998).

- Describing the anger and aggression-inducing situations

- Describing the internal events, including self-evaluations or other cognitions related to the behavior or emotions

- Being aware and observing one's physiological arousal-the arousal process, including early identification and knowledge of its course

- Assessing the type of the aggressive response directed towards oneself or others

- Examining and internalizing the consequences of the aggressive response

- Getting ready to apply alternative cognitive control strategies

- Getting ready to perform alternative behavioral responses

- Getting ready to face the real world (Rose, 1998).

Another major component of the $5^{\text {th }}$ Principle will be advocating for Competency Training (Brach, \& Fraserirector, 2000) on the part of practitioners, most of whom are of European descent (Nakayama \& Martin, 1998; Pinderhughes, 1989; Dominelli, 1989, 1988). Again, an in-depth discussion is not possible here due to the scope of this paper.

\section{Principle 6: Developmentally relevant to the needs of the youth.}

Consideration for the developmental pathways of children and youth at risk is a recurrent decimal in the study of antisocial or conduct behaviors (Hemovich \& Crano, 2009; Mouridsen, Rich, Isager \& Nedergaard, 2008). The LGI process that I postulate here for Black youths and their families takes into consideration the type of family-oriented interactions, the youth's as well as the caregivers' developmental stage. Emphasis is on understanding the youth's stage of cognitive and social development, so that their needs are matched to these variables. For example, it would be pointless to insist and expect a Black youth, who has been in and out of juvenile facilities all his life to pick up where they left off and for instance enroll into school. In this case, MST will be individualized to meet the youth at the level of their cognition. Again, in evaluating the capabilities of some caregivers, especially among 
Blacks, who traditionally practice the extended family system-grandparents, uncles and aunts, consideration is given to the developmental stage of the caregiver.

Where, for instance, the only caregiver is an elderly grandparent, it would appear more challenging, indeed torturous and unfair to leave that grandparent in charge of a grandchild who is presenting with significant antisocial behaviors. Grandmother will burn out, obviously. Another example is with a teenage parent, whose developmental pathway is at par with that of the youth in cognition and social skills. With this scenario, it is doubtful that any parental skills training will make a difference. Here, the enlistment of the support of grandparents and significant others to assist the teenage mother meet some of the adolescent's needs becomes a sine qua non.

\section{Principle 7: Requires daily or weekly effort by family members \& ecological systems.}

MST is predicated on the assumption that antisocial behavior is the sequelae of an individual's interactions with intra and extrafamilial social ecology (Hemovich \& Crano, 2009; Henggeler, et al., 1998). Contingent on this, MST also assumes that these problems can be resolved, only if and when those systems show a political will to expeditiously attenuate or resolve those issues, by removing the barriers that underpin their success. These ecological systems as it concerns Black youths and their families include the youths and their nuclear and extended families, friends, peers, neighbors, social service agents and schools (Pecora, Whittaker, Malucco, Barth, \& Plotnick, 1991). For instance, it would be an exercise in futility, when the school teacher for the multiculturalism class was caught using racial slurs. Or a Black parent, wishing for their child to quit using controlled substances, when they themselves are seen by the youths to be immersed in it. Show me parents who are modeling inappropriate behaviors to their child and I will show you parents having problems controlling this child (Henggeler \& Borduin, 1990).

Principle 8: Intervention effectiveness is continuously evaluated from multiple perspectives and assumption of accountability by providers to overcome successful outcome barriers.

The efficacy of MST hinges, from the perspectives of Henggeler et al. (1998), on continuous and acceptably accurate evaluation of treatment progress, through receiving prompt and constant feedback from stakeholders and key informants. In the case of my proposed LGI and individualized intervention with Black youths and their families suggested for a 4-month duration, I anticipate positive outcomes within 2-4 weeks. Henggeler et al. (1998) suggest 1-2 weeks at the most, but this time frame may not be feasible with Black parents in Canada and the United States. Here, statistics and 
findings by Dickerson (1995); Ruggles (1994); McLoyd, Jayaratne, Ceballo \& Borquez (1994) show the target population to be mostly single mothers, often working in low-paying jobs and having other children to care for, while dealing with a conduct disordered adolescent. 1-2 weeks is hardly long enough to know the participants fully, never mind complete the intervention. This is my reason for suggesting a 2-4-week initial evaluation period. Within this time frame, the feed back from reliable key informants-youths, parents, siblings, teachers, peers, classmates, neighbors and other professionals, will determine whether to continue with the intervention on a group basis, completely individualize the process, seek early alternative perception of the presenting problem, totally abort the current approach or consider alternative solutions.

Two final notes of caution for choosing key informants are those of bias in relation to the validity of the reports or outcomes. For example, a key informant, who also has racist ideologies, will be hard put to reporting the intervention as successful, even when its success is evident. The second caution is about respect for confidential disclosures, when obtaining relevant client information (Fisher, 2008).

\section{Principle 9: To promote treatment generalization and long-term} sustenance of therapeutic change through caregivers' empowerment to negotiate family members' needs with complex multiple systems.

The $9^{\text {th }}$ Principle of MST is intended to assist the sustainable diminishment of antisocial behaviors among Black youths in this communitybased, group treatment setting. This principle assumes that the strides and gains of the treatment in one direction will translate into gains in other ecological systems of the youth and their families. For example, success in getting a Black youth to reduce or reject aggressive behaviors that have implications for conflict within the meaning of the Young Offenders or criminal justice system, is expected to generalize into a concomitant reduction in truancy, shoplifting and other violent acts. Henggeler, et al. (1998), argue that designing intervention approaches that engender generalization and maintenance have promising implications for the MST practitioner, who must be guided by these under listed rules.

Capitalize on the development of skills relevant for the family to navigate and negotiate their social environment.

* Strengthen family members' capacity to negotiate present and future problems

*aregivers charting their own social environment and therapists playing only supportive and consultative roles, will evolve as empowering tools for rejecting the ascribed pathology of Black families (Geary, 2015). 
Capitalize and highlight already existing family strengths, capabilities and know-how. Often Black families as Geary surmises, are judged using a deficit, rather than a strength based approach, with predictable outcomes

Extensively utilize protective and resiliency characteristics available in the family and the family's natural ecology. In the case of Black families, the existence of traditional and extended families-uncles, aunts, cousins, grandparents, townsfolk, etc., present as protective factors (Glicken, 2004). Conversely, the current ability of Black families to continue to thrive under the aegis of slavery, racial prejudice and social exclusion in the United States, Canada and elsewhere are proven indices of its resiliency.

\section{Discussion}

Intervention theory \& outcomes of MST in the United States of America: Findings from Controlled Evaluations.

The Multisystemic Therapy in the US became the sine qua non of conduct disordered interventions in America and Canada for many years. This was based on randomized studies carried out by researchers, chiefly, Scott Henggeler and his team, at the Medical University of South Carolina and Columbia, Missouri (Henggeler, et al., 2009). The developers' basic assumptions and arguments, based on these studies is that MST could be a cost-effective, community-based intervention modality to reduce the Intake of high-risk youth in residential facilities.

Since the inception of the MST in the 1970s, there have been a few studies related to arrest outcomes. The first, 1978-1983 on Inner-City Delinquents (Fegan, Piper \& Cheng, 1987-1988), used a quasi-experimental design and comparison participants, selected from diversion program case files to match the demography of the families in the MST condition. Pre and post treatment tools, including self-report, observational measures and other reports were utilized. Outcomes of MST with this study showed the following:

$>$ More than the usual community services, MST was found to be efficacious in increasing family relations with regard to communication and affect, as well as decreasing disordered adolescent conducts. This finding is extrapolatable, using my proposed Large Group Intervention paradigm with conduct disordered Black Youth in the United States and Canada

$>$ A second finding was that improved family relations as a result of MST post-treatment, corroborated the social ecological treatment theory of MST. The social ecological treatment theory is predicated on an assumption that delinquent behaviors emanate from the dovetailing or intercourse of environmental, rather than individual or family factors alone (Zembroski, 2011). Black youth are a product of 
their environment, which began with slavery, the evolution of matriarchies, racial discrimination-leading to poverty and domicile in poverty accumulation neighborhoods, high drop-out rates in education, police brutality and the current disparities in the criminal justice system. These in turn, have led to the current, but pervasive School to Prison Pipelines axiom and experience that has become Black youth destruction pathway, since the end of slavery and the Jim Crow Laws.

$>$ The third finding suggested that MST may be relevant in conducting further studies for the treatment of other serious clinical problems as the next segment indicates.

Chronic Juvenile Offenders: Outcome study of this population by Borduin et al. (1995), using randomized trials based on MST versus other methods, indicated that MST was helpful in effecting those types of changes in family functioning and dynamics. It found MST to be catalytic to the reduction of delinquency in chronic juvenile offenders. These family dynamics or functioning included family cohesiveness (Glicken, 2004), adaptability, supportiveness, decreased hostility and parents' psychiatric symptomatology (Henggeler et al. 2009; Henggeler, et al.,1998).

\section{MST as a Cost-Effective alternative to incarceration of Violent \& Chronic Juvenile Offenders:}

MST's claim to efficacy and cost-effectiveness in treating this population, rather than the capital intensive and recidivist outcomes of incarceration was challenged through the collaboration of Department of Mental Health and the Department of Juvenile Justice (Henggeler et al., 1998). The scope of this paper precludes detailed discussion, but suffice it to say that MST results in the US trials showed its efficacy in reducing delinquent behaviors, rearrests and incarceration. Findings from a 2-4-year follow-up, showed that MST has a long-term effect of reducing reoffending or recidivism. On the issue of costs, the MST trial in the Simpsonville project as against incarceration, indicated that MST reduced incarceration by an average of 73 days per offender over a 59 -week follow-up. This was assumed to be equal to $\$ 7,300$ US per youth for incarceration and between $\$ 4,000$ to $\$ 5,000$ per family, with MST intervention (Henggeler et al.,1998). MST as a cost-effective alternative to incarceration may be facing an uphill battle, especially with the recent gluttony in the United States for privatized incarceration, which has become a cash cow for American corporations (Etter, 2017). The question becomes, "why should American entrepreneurs care one hoot about MST or the LGI, hybrid which we propose? Do they not stand to cash in on large scale incarceration of 
people, especially, Black and Brown bodies amidst them, who are prima facie in high vulnerability?"

Now, please, tarry with us as we examine MST implementation and outcomes in Ontario, Canada to underscore it efficacy in multiple layered application. Extrapolate this to Large Group Intervention spaces, which we propose and the gains may be even higher.

\section{MST Implementation \& Outcomes in Ontario cities of Simcoe County,} Mississauga, London \& Ottawa:

MST experiments in these Ontario cities of Simcoe County, Mississauga, London and Ottawa from April 1997 to March 2001, were attempts to evaluate whether the American results would generalize to Canada (Leschied, Cunningham, \& Dick, 1998). Unlike the American outcomes based on arrests, that of Ontario had an outcome based on criminal conviction. As well, they were predicated on the ecological model, which placed findings and subsequent recommendations in the context of the implementation environment. Contingent on this, the Ontario experiment, comprising 409 families was buttressed on research literature that argued that MST was efficacious, effective and efficient in reducing recidivism rates among a group of youth. These youths exemplified chronic presentation with criminal behavior, which may translate into challenges for both the existing social services, and concerns among the population in Ottawa, London, Simcoe County and Mississauga. The overriding aim of MST in Ontario was to ascertain if MST will be followed by reduced levels of recidivism and correctional services' burgeoning expenditures than currently existing services. Criminal convictions if any, of these 409 youths was tracked until 2004 (Leschied, Cunningham, \& Dick, 1998).

Research Design-Ontario, Canada: The study used the experimental design and definitive methodology to test the intervention. It also used clear selection criteria, large samples, multi-environment, longitudinal follow-up, as well as simple outcome measures. Of note is that the investigators used were independent of the MST developer.

Findings of the Ontario MST studies/experiment tracking the recidivism of 380 youths during a period of three years up to September 2001

- 80 percent of the sample had been convicted at least once within three years following discharge

- Two-thirds of the sample had been convicted of an offense after two years

- When criminal behavior is the target outcome, MST or usual social services will do little to prevent criminal behavior and subsequent conviction 
- The seriousness of offenses committed by recipients in the follow-up period did not appear to have been impacted by the MST intervention

- Conservative fiscal estimates so far for the 409 youths in the study was $\$ 43$ million at the rate of $\$ 6,000-\$ 7,000$ per family, in addition to MST fiscal votes for training, supervision and licensing (Leschied, Cunningham, \& Dick, 1998).

Some of the reasons attributed to the statistically limited success of MST in Ontario include the following:

- Sample size previously estimated at 800 was only 409- too small for appropriated randomization to be effective.

- The Training Protocol, where supervision/consultant experts were done through telephone/teleconference may not standardize the study

- In the real world, there appears to be a high turnover rate or Therapist attrition in child welfare and young offenders

- Participation in MST is strictly based on the youth's and family's volition. They can choose not to attend

- Improvements in various life areas do not always and necessarily translate into reduced recidivism rates in criminal behavior

- Pre-tests are completed at a time of crisis, while Post-test results may simply be showing the family's return to baseline levels.

\section{Some gains of MST in Ontario, Canada}

- MST participants and parents reported improvements in family adaptability and functioning, reduction in caregiver depression and externalizing and internalizing symptoms of youth-depression, anxiety; increase in self-esteem and self-worth (Leschied, Cunningham, \& Dick, 1998).

- MST recipients were more likely to be sentenced to open custody, rather than secure custody

- MST completers had less recidivism rates than drop-outs or usual social services group

- Although MST is very capital intensive, it is suggested that this high expenditure will be compensated for by savings in the correctional system

- In Ottawa, 38 percent of MST recipients had no running with the police, compared to 28 percent for the usual social service group (Leschied et al., 1998).

\section{Evaluation procedure \& pertinence of the proposed LGI paradigm}

Currently, there appears to be no Multisystemic Therapy of the Large Group Intervention-[LGI] paradigm targeted to Black youths in the United 
States and Canada, within the meaning of the Young Offenders Act or those presenting with a high risk of conduct disorders or criminal behaviors. This disinterest, especially in the United States is contingent on the current gettough-on crime ethos, which platform is akin to swatting a fly with a bazooka. In the case of the United States, having the highest incarceration rates than any country in the world, punitive, rather than restitutive models have now become ingrained in the psyche of both its populace and the juvenile and criminal justice systems. There is a finding by Kirchhoff (2010) that by the end of 2008, there were approximately 2.3 million adults in state, local, or federal custody in the US. Kirchhoff further supplied that another 5.1 million Americans were on probation or parole. Of that total, 9 percent were in federal custody. The poignancy of this finding is that from a global prism, the United States comprises only 5 percent of the world's population but paradoxically "hosts" 25 percent of the world's prisoners. This number surpasses Russia, which previously held this notoriety and China, which has a population of approximately 1.2 billion inhabitants.

Additionally, incarceration in America has become a multibillion dollar enterprise, where individuals now own and operate private for-profit prisons (Schultz, 2015). In this context, an evaluation procedure for our proposed Large Group Intervention-LGI, MST application among Black youth will be challenging, but would essentially be based on what exists within Canada's Young Offenders Justice System-Alternative Measures Program, Restorative Justice, Aggression Replacement and Residential placement (Department of Justice, Canada, 2017). Other procedures for evaluating the efficacy of this program would be through rapid and constant feedbacks from key informants and major stake holders, including report and surveys garnered through group members.

\section{Implications of Multisystemic Therapy for policy, practice and future research}

One significant criticism of the MST approach is its multi-dimensional structure that presents a challenge in deciding which treatments to apply in a given case (Kadzin, 1995). Regardless of the various critiques of the MST, based mainly on its efficacy, effectiveness and efficiency, there does not appear at the present to be any existing alternative for treating youths and their families presenting with serious conduct and criminal behaviors, either in Canada or especially in the United States. Henggeler et al. (1998); Henggeler (1997), have argued that MST has significantly successful implications, in both areas of clinical outcomes and cost savings. On the contrary, they argue that the existing social services structures have continued to expend large amounts of fiscal and personnel resources, without accompanying significant 
positive outcomes. Below are some of the policy implications as outlined by Henggeler et al. (1998).

- Increase in Family and Community-Based Services in contrast with Residential and Institutional Services

- Accountability of Service Providers-Therapists, supervisors and administrators in engaging families in the treatment regimen, as well as attaining the expected clinical and fiscal outcomes

- MST protocol that requires continuous and on-going quality improvement through personnel training, since MST fidelity and clinical outcomes are ordinarily difficult to achieve

- I add and argue that for any intervention to be successful, it must have funding and one that is sustainable

Extrapolated MST intervention, using LGI among Black Youth in the United States and Canada

Are MST and its hybridized LGI paradigm a one-size-fits-all? Hardly! Whereas LGI-MST intervention may prove to be effective with some populations, such as the Black community and other minorities, it may not hold true for others within the dominant culture. The reason for the suggested effectiveness of MST for Black youths and their families bestride the variables that define Black populations in the United States and Canada-racism, social exclusion, poverty and occupation of the lower socio-economic stratum. Others are the presence of a large number of young persons in juxtaposition with the populations and more single, female headed house-holds and domicile in poverty accumulation neighborhoods.

For the Black youth and their families in Montréal, Canada, for instance, what exists at the present is a high rate of adjudication and residential placement. To this extent, any intervention at all, including MST, especially using Large Group Intervention-LGI modality is worth trying. It can be applied to evaluate how effective it portends for reducing, not only behaviors that bring Black youths and their families into the system, but also one that reduces the recidivism rates.

\section{Successful management of MST Large Group Intervention-LGI process}

Are the goals of MST using Large Group Intervention-LGI modalities attainable? The answer lies in the type of technique applied, when engaging large groups such as we have proposed here. What are some of the ways of attaining successful outcomes, when large groups are involved? Bunker (2005, 1992a); Turqet, (1975) suggest the following:

a. A "divide and conquer" process that involves using small groups [mezzo] to stimulate discussion, thereby promoting engagement by the participants 
b. Application of self-management and a democratization process to assume responsibility for task and program outcomes

c. Again, using a democratization process, including voting, to maximize latitudes for individual choice options

d. Create large group reports to share collective understanding, including gains made, group learning and esprit de corps

e. Ensure productivity and successful outcomes, by maximizing the amount and quality of structure pertinent to contain individual and group anxiety

f. Through well-thought out member selection and grouping, promote diversity, encourage holistic thinking, group consciousness and solidarity

\section{Conclusion}

The following was an attempt to articulate conduct disorders in children and adolescents. Pertinently, it was an attempt to examine and implement efficacious preventive and treatment approaches to address antisocial behaviors among Black youths in the 12-18 cohort population. The paper had its fulcrum on two major components. The first was on how disordered conduct and antisocial behaviors bring Black youths and their families into conflict with the Young Offenders and Adult criminal Justice systems in the United States and Canada. The second was to find an intervention approach, the Large Group Intervention paradigm, [extrapolated from Scott Henggeler's Multisystemic therapy] that presents as efficacious and especially sustainable in preventing and treating criminal behaviors, as well as reducing the recidivism rates among those who have experienced conflict with the Juvenile Justice System.

The first part of the paper used Black youths and their families as a target population, based on their externalizing manifestations, and burden of suffering. Research findings on Black youths in Montréal, one of which was based on a cross-sectional study design, buttressed the assumption that there is a preponderance of Black youths and their families in the Juvenile Justice System in comparison to the general Canadian population. The developmental stage of the Black youths that was used in the LGI proposal was adolescents and youths between the ages of 12 to 18 . This is due to the visibility, rapid physical and social mobility-including digital and social media mobility and conectivity of this cohort in the general population. Poignant to this intervention is that the Black population has more young persons in their families than the general US and Canadian population, therefore more likely to come into contact and mostly conflict with the Juvenile Justice system.

The intervention was LGI-community-based and targeted to Black youths, due to the Black population's experience with slavery, racial 
discrimination and social exclusion. It was also targeted to Black youths and their families, owing to research findings that Black families are mostly poor, stereotyped, have many children and have more single parent households, mostly headed by women. In formulating a treatment model, we used the Multisystemic Theory approach (MST) as espoused by Scott Henggeler and his team, based on its Nine Treatment Principles. The crux of MST that it is predicated on antisocial behavior, as being multidetermined by the interplay between the youth and the various social systems, with which they interact, is particularly apt with Black youths and their families. The identified social institutions constitute the school environment, including teachers, most of whom are White, neighborhood, peers, the police and other law-enforcement agents, leading to the current "School to Prison Pipeline" cliché. This is due to their history of conflict and marginalization by the dominant culture. However, due to the constraints posed by funding within the helping systems, including the Black community, I adapted this usually Home-Based, Individualized approach into a community-based, Large Group InterventionLGI-setting to benefit more youths, not only from the program, but through contiguity and close interaction and reinforcement, share and acquire prosocial skills.

The sum total of the Nine Principles of MST as it applies to and proposed for Black youths and their families to prevent contact with and reduce recidivism within the Juvenile and criminal Justice systems, implied the following: empowerment for parents to better control and provide supervision for their youths; empowerment for the Black youth themselves, including promoting responsible behaviors. It also proposes addressing some dysfunctional dynamics in the family and social systems that will conversely reduce criminal behaviors and contact with the justice system. The intervention included Competency Training for practitioners in the social systems, which are in interaction with the youths and their families.

Our attempt to evaluate and contextualize MST in terms of efficacy, effectiveness and efficiency saw this paper comparing studies carried out by the designers, Henggeler and team in the US and that replicated in four cities in the province of Ontario, Canada. The findings showed that whereas that in the US succeeded somewhat, those in Ontario, even when controlling for some gains, failed to elicit significant differences in after treatment convictions. Some of the reasons adduced were those due to the differences in research designs, the configuration of study participants, as well as the socio, political, economic and cultural nuances that differentiate the two countries. This is the raison d'être of my proposed LGI paradigm. In terms of cost effectiveness, MST was found to be expensive to implement, but paled in fiscal cost when compared to incarceration, institutionalization or out-of-home placement. 
In terms of its pitfalls, MST was found to be a little unwieldy to manage due, to the existence of too many components, including Large Group Interventions-LGI, which may make it difficult to decide which principles to apply to a particular clientele. Some of the identified practice, policy and future research implications showed that there are currently no serious contenders to MST, based on findings in the US. Since the findings in Canada are not necessarily tallying with those in the US, further research into this approach may be the best way of establishing realistic outcomes. Again, in terms of outcomes, it is suggested that MST's successes may depend on the type of clientele or population to whom it is applied. In this regard, we strongly suggest that LGI-MST be tried with Black youths and families at risk, due to the homogeneity of their experiences as a minority group in the United States and Canada. The other reason is the fact that Black youths and their families in these two contiguous countries belong to, are lumped, defined and treated in terms of this externally imposed social category, which places them at a higher risk than any other racial and social category.

\section{References:}

1. American Psychiatric Association (2013). Diagnostic and Statistical Manual of Mental Disorders (DSM-5) (5 ${ }^{\text {th }}$ Ed.). Washington DC: American Psychiatric Publishing.

2. American Psychological Association (2008). Are Zero tolerance policies effective in the schools? An evidentiary review and recommendations. American Psychological Association Zero Tolerance Task Force. American Psychological Association 63(9), 852-862.

3. Barn, R. (1993). Black Children in the Public Care System. London: B.T. Batsford Ltd.

4. Brach, C. \& Fraserirector, I. (2000). Can cultural competency reduce racial and ethnic health disparities? A review and conceptual model. Medical Care Research and Review, 57(1), 181-217.

5. Brown, J. (2008). A discussion of common challenges and confusion about the usefulness of Murray Bowen's family systems approach. Journal of the Counsellors and Psychotherapists Association of NSW. 3: 11-17.

6. Bunker, B. B., Alban, B. T. (2005). Introduction to the special issue on large group interventions. Journal of Applied Behavioral Science, 41, 9-14.

7. Bunker, B., Alban, B. (1992a, December). Conclusion: What makes large group interventions effective? Journal of Applied Behavioral Science, 28, 579-591. 
8. Burkhead, D. M. (2006). The search for the causes of crime: A history of theory in criminology. New Carolina: McFarland \& Company, Inc., Publishers.

9. Curtis, N. M., Ronan, K. R., \& Borduin, C. M. (2004). Multisystemic treatment: A meta-analysis of outcome studies. Journal of Family Psychology, 18(3), 411-419.

10. Department of Justice Canada (2017). The Youth Criminal Justice Act Summary and Background. Author. Retrieved from: http://www.justice.gc.ca/eng/cj-jp/yj-jj/tools-outils/back-hist.html

11. Dickerson, B. J. (1995). African American Single Mothers: Understanding Their Lives and Families. Thousand Oaks, California: Sage Publications, Inc.

12. Dominelli, L. (1989). An Uncaring Profession? An Examination of Racism \& Social Work. New Community, Vol. 15, No. 3.

13. Dominelli, L. (1988). Anti-Racist Social Work. A Challenge for White Practitioners. Basingstoke: Macmillan.

14. Dwivedi, Kedar. Nath. (1993) (ed.) Group Work with Children \& Adolescents: A Handbook. London \& Bristol; Pennsylvania: Jessica Kingsley Publishers.

15. Etter, L. (2017, January 10). America's private prisons are back in business. Bloomberg. Retrieved from: https://www.bloomberg.com/news/articles/2017-01-10/trumpdeportation-plan-to-hand-windfall-to-a-dying-u-s-industry

16. Fisher, M.A. (2008, January). "Protecting Confidentiality Rights: The Need for an Ethical Practice Model” American Psychologist 63(1), Pp.1-13.

17. Gardner, Richard. A. (1999). Psychotherapy of Antisocial Behavior \& Depression in Adolescence. North, New Jersey; London: Jason Aronson Inc.

18. Geary, D. (2015). Beyond Civil Rights: The Moynihan Report and Its Legacy. Philadelphia, PA: University of Pennsylvania Press.

19. Glicken, M. D. (2004). Using the strengths perspective in social work practice. Boston: Pearson.

20. Harlos, K. P., Mallon, M., Stablein, R., \& Jones, C. (2003). Teaching qualitative methods in management classrooms. Journal of Management Education, 27(3), 304-322.

21. Hawkins, D. (1995). Ethnicity, Race, \& Crime: Perspectives Across Time \& Place. New York: State University of New York Press.

22. Henning, K. N. (2013). Criminalizing Normal Adolescent Behavior in Communities of Color: The Role of Prosecutors in Juvenile Justice Reform. Cornell Law Review, Vol. 98, pp.383-462. 
23. Henggeler, S. W. (1997). Treating serious anti-social behavior in youth: The MST approach. Juvenile Justice Bulletin, U.S. Department of Justice, Office of Justice Programs, Office of Juvenile Justice \& Delinquency Prevention.

24. Henggeler, S. W. (1996). Treatment of Violent Juvenile Offenders-We Have the Knowledge: Comment on Gorman-Smith et al. Journal of Family Psychology, 10, 137-141.

25. Henggeler, S.W. \& Borduin, C. M. (1990). Family Therapy \& Beyond: A Multisystemic Approach to Treating the Behavior Problems of Children \& Adolescents. Pacific Grove, California: Brooks/Cole Publishing Company.

26. Henggeler, S, W.; Letourneau, E. J.; Chapman, J. E.; Borduin, C. M.; Schewe, P.; McCart, M.R. (2009). Mediators of change for multisystemic therapy with juvenile sexual offenders. Journal of Consulting and Clinical Psychology, Vol 77(3), 451-462. http://dx.doi.org/10.1037/a0013971

27. Henggeler, S.W., Mihalic, S.F., Rene, L.; Thomas, C. \& TimmonsMitchell, J. (1998). Blueprints for violence prevention: Multisystemic Therapy. Boulder, CO: Center for the Study \& Prevention of Violence.

28. Henggeler, S. W., Schoenwald, S. K., Borduin, C. M., Rowland, M. D., \& Cunningham, P. B. (1998). Multisystemic Treatment of AntiSocial Behavior in Children and Adolescents. New York: Guilford Press.

29. Hemovich, V. \& Crano, W.D (2009). Family structure \& adolescent drug use: An exploration of single-parent families. Substance Use and Misuse, 44(14), 2099-2113.

30. Herbert, Martin. (1987). Conduct Disorders of Childhood \& Adolescence: A Social Learning Perspective. Chichester, UK: John Wiley \& Sons.

31. Hutchinson, Y., Nichols, B., Pare, N., \& Pepin, M. (1992). Profile of Clients in the Anglophone Youth Network: Examining the Situation of the Black Child. (Research Committee on Batshaw, Association of Black Human Services Workers; McGill School of Social Work; VMSSC).

32. James R., Blair, R., Leibenluft, E. \& Pine, D, S. Pine (2015). Conduct disorder \& callous-unemotional traits in youth. New England Journal of Medicine 372(8), p.784. DOI: 10.1056/NEJMc1415936

33. Joseph, J. (1995). Black Youths, Delinquency, and Juvenile Justice. Connecticut: Praeger Publishers.

34. Kadzin, Alan. E. (1995). Conduct Disorders in Childhood \& Adolescence. (2 ${ }^{\text {nd }}$ Edition, Vol. 9) Developmental Clinical Psychology \& Psychiatry. Thousand Oaks; London; New Delhi: Sage Publications. 
35. Kirchhoff, S.M. (2010). Economic impacts of prison growth. Washington, DC: Congressional Research Service.

36. Leschied, Alan.W., Cunningham, Alison., Dick Trish. (April 1998). Clinical Trials of MST with High Risk Phase 1 Young Offenders, 1997 to 2001. Year End Report 1997/1998. London: Family Court Clinic.

37. Li, P. (1990). Race \& Ethnic Relations in Canada. Toronto: Oxford University. Mallett, C. A. (2016). The School-to-Prison Pipeline: Disproportionate Impact on Vulnerable Children and Adolescents. New York: Springer Publishing Company.

38. McCord, J. \& Tremblay, R.E. (1992). Preventing Antisocial Behavior: Interventions from Birth through Adolescence. New York; London: The Guilford Press.

39. McLoyd, V. C., Jayaratne, T. E., Ceballo, R., \& Borquez, J. (1994). "Unemployment and work interruption among African American single mothers: Effects on parenting and adolescent socioemotional functioning." Child Development, 65(2), 562-589. Medical University of South Carolina (n.d.). MST for Emerging Adults (MST-EA) Adaptation of Multisystemic Therapy for Transition-Age Youth. MUSC.

Retrieved from: http://academicdepartments.musc.edu/psychiatry/divisions-andprograms/dgch/subsites/mstforea.htm

40. Miller, R., Anderson, S., \& Keala, D. (2004). Is Bowen theory valid? A review of basic research. Journal of Marital and Family Therapy 30(4), 453-466.

41. Minuchin, P.P. \& Shapiro, E.K. (1983). The School as a Context for Social Development. In Hetherington, E. M. (Ed.), Handbook of Child Psychology, Vol. 4: Socialization, Personality, \& Social Development. New York: Wiley.

42. Mosher, C.J (1997). Discrimination \& Denial: Systematic Racism in Ontario's Legal \& Criminal Justice System 1892-1961. Toronto: University ofToronto Press.

43. Mouridsen S.E, Rich B, Isager T, \& Nedergaard, N.J. (2008). Pervasive developmentaldisorders and criminal behavior: A case control study. International Journal Offender Therapy Comparative Criminology, 52(2), 196-205.

44. Nakayama, T. K. \& Martin, J. N. (1998). Whiteness: The Communication of Social Identity. London, New Delhi. Sage Publications.

45. National Council on Crime and Delinquency (2007). And Justice for Some: Differential Treatment of Youth of Color in the Justice System. Author, Oakland, CA. Retrieved from: 
http://www.nccdglobal.org/sites/default/files/publication_pdf/justicefor-some.pdf

46. Pecora, P., Whittaker, J., Maluccio, A., Barth, R., \& Plotinick, R. (1991). The Child Welfare Challenge: Policy Practice \& Research. N.Y.: De Gruyter.

47. Peters, R. DeV \& McMahon, R. J. (1996). Preventing Childhood Disorders, Substance Abuse, \& Delinquency. Banff International Behavioral Science series. Thousand Oaks; London; New Delhi: Sage Publications: International Educational \& Professional Publisher.

48. Piaget, J. (1932). The Moral Judgment of the Child. New York: Harcourt Brace.

49. Pinderhughes, E. (1989). Developing Diversity Competence in Child Welfare \& Permanency Planning. The Haworth Press Inc.

50. Ray, M. (1995). A metaphor for worldwide paradigm shift. In K. Gordz (Ed.) Community building: Renewing Spirit and Learning in Business. San Francisco, CA: Sterling \& Stone, Inc.

51. Rose, Sheldon. D. (1998). Group Therapy with Troubled Youth: A Cognitive-Behavioral Interactive Approach. Thousand Oaks; London; New Delhi: Sage Publications.

52. Ruggles, S. (1994, February). The Origins of African-American Family Structure.American Sociological Review, 59(1), 136-151.

53. Russell, K. (1997). The Color of Crime: Racial Hoaxes, White Fear, Black Protectionism, Police Harassment \& Other Macroaggressions. New York: New York University Press.

54. Schissel, B. (1990). Social Dimensions of Canadian Youth Justice. Toronto. Oxford.Schoenwald, S. K., Heiblum, N., Saldana, L. \& Henggeler, S. W. (2008). The international implementation of Multisystemic Therapy. Evaluation \& the Health Professions 38(3), 429.

55. Schultz, C. (2015). Prison Privatization: Driving Influences and Performance Evaluation. "Themis: Research Journal of Justice Studies and Forensic Science, 3(1), Article 5.

56. Sutherland, Edwin. H., Cressey, Donald. R., \& Luckenbill, David. F. (1992). Principles of Criminology. New York: General Hall.

57. The Sentencing Project (2013). Regarding racial disparities in the United States criminal Justice system. Report of the Sentencing Project to the United Nations Human Rights Commission.

58. Torczyner, J.L. (1997). Diversity, Mobility \& Change: The Dynamics of Black Communities in Canada. Canadian Black Communities Demographic Project. Preliminary Findings. Montreal: McGill University, McGill Consortium for Ethnicity \& Strategic Social Planning. 
59. Vitaro, F., Mara Brendgen, M., \& Wanner, B. (2005). "Patterns of Affiliation with Delinquent Friends During Late Childhood and Early Adolescence: Correlates \& Consequences." Social Development 14(1), 82-108.

60. Vostanis, P. (2017, October 17). Editorial: Global child mental healthEmerging challenges \& opportunities. Global Child Mental Health 22(4), 177-241.

61. Walker, S., Spohn, C. \& DeLone, M. (2000). The Color of Justice: Race, Ethnicity \& Crime in America. Belmont, CA; London: Wadsworth/Thomson Learning.

62. Weijers, I. (2004). Delinquency and law. In J. Jansz \& P. van Drunen (Eds.). A Social history of psychology (Pp.195-219). Oxford: Blackwell Publishing.

63. Zembroski, D. (2011). Sociological Theories of Crime \& Delinquency. Journal of Human Behavior in the Social Environment, 21(3), 240254. 